\title{
The Prediction Of Flexibility And Its Relationship With Work Variables
}

\author{
René van Wyk, University of Johannesburg, South Africa \\ Mandla Adonis, Gordon Institute for Business (GIBS), University of Pretoria, South Africa
}

\begin{abstract}
The adaption of flexible practices is a necessity for businesses to be able to survive in a global competitive environment in support of entrepreneurial and market intelligence. This study explores the prediction of formal flexible practices compared with inflexible authoritarian business practices in a South African sample of 333 managers and supervisors. A Pearson Product-Moment Correlation between flexible and inflexible practices with corporate entrepreneurship, market orientation and job satisfaction revealed almost direct opposites of the coin. Extrinsic job satisfaction, management support and risk acceptance explained most of the variance in the prediction of both formal flexibility and inflexible authoritarianism by means of Hierarchical Multiple Regression. Management should be vigilant of the opposing relationships of flexible and inflexible work practices in business. Organizations should explore methods to adapt formal flexible practices supported by entrepreneurial and marketing orientations, as well as extrinsic job satisfaction. Management must particularly guard against inflexible authoritarianism and its adverse effects.
\end{abstract}

Keywords: Flexibility; Inflexibility; Competitiveness; Innovation

\section{INTRODUCTION}<smiles>[C]1C=CC=C1</smiles>

olatile, uncertain economic environments demand change, and flexible business practices provide a platform for adaptable and responsive systems that enhance productivity (Thatte, Rao \& RaguNathan, 2013; Kuye, Abiola \& Oghojafor, 2013) and performance (Grewal \& Tansuhaj, 2001). Although normal operations are predictable, flexible practices are essential to accommodate variability for exceptions, new developments (Reichert \& Weber, 2012), fluctuating market conditions (Grewal \& Tansuhaj, 2001) and taking control of environmental uncertainty and economic crises, especially in the developing world (Grewal \& Tansuhaj, 2001). Flexibility is seen as the ability of a business to generate strategies, and provide situational expertise to adapt to market challenges (Arief, Thoyib, Sudiro \& Rohman, 2013; Bhardwaj \& Momaya, 2006) and accomplish commercial excellence (Halemane \& Janszen, 2004). The ability of businesses to strategically exploit environmental changes, and turn them into opportunities of sustained market presence (Gjerding, 1999) needs to be supported by flexible management practices (Chen, Fabozzi \& Haung, 2013). Conversely, low flexibility would imply strict compliance to administrative and bureaucratic procedures. Competitive flexible practices are essential for supporting the unpredictable fierce market demands (Sabbaghi, 2004), and securing continuous progress in meeting customer needs (Kadir \& Nadarjah, 2012).

Businesses compete in economic environments where the speed of change is escalating (Kuye et al., 2013). Kukalis (1989) proposed the notion that planned flexibility as a strategic planning of systems can maximize performance in challenging economic environments. Flexible practices strategically close the gap between market demands and the provision by the firm (Halemane \& Janszen, 2004). For this reason flexible information distribution should be a key organizational strategy as it leads to long-term performance (Arief et al., 2013; Ramirez, Morales, \& Aranda, 2012). Flexible strategic planning enhances the capacity of a business to adopt and change as opportunities and/or threats emerge (Barringer \& Bluedorn, 1999). Proper management of flexibility could maximise value (Sabbaghi, 2004), control risk management, and increase revenue in uncertain markets (Bhattacharya \& Giapponi, 2007). It is, however, important that flexibility practices in production are thoroughly 
monitored by means of sophisticated accounting systems (Venieris \& Cohen, 2008). Under controlled conditions, flexible work practices are related to an increase in business performance (Ramirez et al., 2012), competence (Olalekan, 2011), enhanced productivity and morale, as well as a decrease in absenteeism and turnover (Grobler \& De Bruyn, 2011).

Process flexibility takes place when an organization creates ground-breaking methods to generate new developments under controlled conditions (Kadir \& Nadarjah, 2012). Flexible planning should support entrepreneurial initiatives in the continuous scanning of the entrepreneurial environment opportunities and threats (Barringer \& Bluedorn, 1999). This allows for the occurrence of exceptional processes, preventing inertia and inflexibility (Barringer \& Bluedorn, 1999) without violating organizational objectives and compliance with policies (Kadir \& Nadarjah, 2012; Reichert \& Weber, 2012). Different forms of flexibility can improve supply-chain resources, and provide the capacity of product-flow demand in target markets (Sabbaghi, 2004).

\section{LITERATURE REVIEW}

Flexibility is regarded as an operational problem-solving strategy of management in uncertain entrepreneurial environments (Kuye et al., 2013). This discussion examines the relationship of corporate entrepreneurship, market orientation and job satisfaction with organizational flexibility. This investigation should shed light on the important role that management plays in the facilitation of flexible practices by accommodating corporate entrepreneurship, market orientation and job satisfaction principles.

Corporate entrepreneurship is regarded as the innovative business development and strategic regeneration of established firms (Guth \& Ginsberg, 1990), leading to transformation and advancement (Ribeiro-Soriano \& Urbano, 2010). A significant positive relationship between flexibility and corporate entrepreneurship is confirmed (Barrett \& Weinstein, 1998; Barringer \& Bluedorn, 1999). Flexibility in combination with corporate entrepreneurship is seen as the entrance to new venture development (Bhardwaj \& Momaya, 2006). The flexibilitycorporate entrepreneurship combination should advance competitive new venture technology and product development (Bhardwaj \& Momaya, 2006). Arief et al. (2013) report that strategic entrepreneurial orientation, with flexibility as mediator had a significant positive common variance in firm performance as the predictor variable of 0.623 .

Entrepreneurial orientated firms create new markets and generate new opportunities in existing markets (Zortea-Johnston, Darroch \& Matear, 2012). Market orientation refers to the distribution of market information of existing and prospective needs of customers (Kohli, Jaworski \& Kumar, 1993), supported by internal coordination of functions to supply market needs (Narver \& Slater, 1990). A business can only operate with an effective market orientation if it has flexible business practices (Bhardwaj \& Momaya, 2006). Market orientation showed a significant positive correlation with strategic flexibility $(r=.48 ; p=0.01)$ in a sample of 120 Thai managers (Grewal \& Tansuhaj, 2001). Market orientation and flexibility should be reinforced simultaneously to aid management in dealing with challenges of economic crises (Grewal \& Tansuhaj, 2001).

As far as could be ascertained the relationship between organizational flexibility and job satisfaction has not been investigated previously. Job satisfaction is regarded as a reflection of an individual's feeling about his or her various job characteristics, implying emotional well-being (Spector, 1997). We argue that job satisfaction play an important role in flexible management practices, as job satisfaction is regarded as a principal work variable with direct and indirect advantages (Keller \& Semmer, 2013).

Due to the important role that flexibility plays in adapting to business demands, its relationships with the work variables of corporate entrepreneurship, market orientation and job satisfaction are investigated. These relationships are illustrated in Figure 1. 


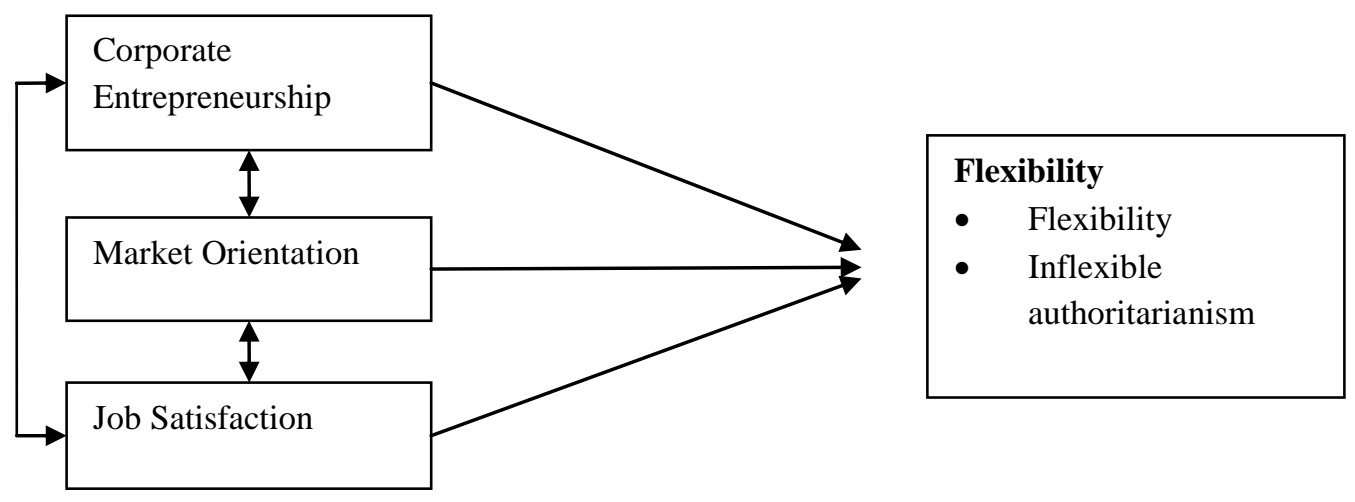

Figure 1: The Relationships between Corporate Entrepreneurship, Market Orientation and Job Satisfaction with Flexibility

The research questions related to Figure 1 are the following:

- $\quad$ Research question 1: What is the relationship between flexibility and business variables in the form of corporate entrepreneurship, market orientation and job satisfaction?

- $\quad$ Research question 2: What is the relationship between inflexible authoritarianism and work variables in the form of corporate entrepreneurship, market orientation and job satisfaction?

- Research question 3: To what extent is flexibility predicted by the work variables of corporate entrepreneurship, market orientation and job satisfaction?

\section{METHOD}

A non-random convenience sample of participants was selected, and a self-administered questionnaire was applied. Participants represented four South African economic sectors, namely life insurance, information technology, university and transport parastatals. Participants were assured of the confidentiality and anonymity of information. The questionnaire included a letter introducing the researchers and stating the reason for the study. The questionnaire had both psychometric instruments measuring flexibility, corporate entrepreneurship, market orientation and job satisfaction. A non-random sample of 396 individuals participated. Thirty-six questionnaires were rejected due to incomplete responses to the psychometric scales. Only 333 fully completed questionnaires could be used. These represented responses from managers and supervisors from four economic sectors.

\section{Participants}

The convenience non-random sample consisted of 144 males and 187 females (two did not indicate their gender), with ages ranging between 21 and 70 years (mean of 36.66 and standard deviation of 9.26 years). Most of the participants were married (194), 82 were not married, 36 divorced, 11 co-habiting, seven widowed and one estranged (two participants unreported). The home language of the participants was declared as mainly English (202), followed by Afrikaans (86), and African languages (45). The majority of the participants were South African citizens (326), four where non-South African and three did not indicate their citizenship. Seven participants did not indicate their qualifications. The academic qualifications of the participants were reported as: $46=$ secondary school without Grade 12, Grade $12=87,105$ post-school certificate or diploma, $38=$ bachelor's degree, $33=$ honours degree, and $17=$ master's degree.

\section{Measuring Instruments}

The 10 item, seven-point Organizational Flexibility Scale by Khandwalla (1987) measured the flexible formal and inflexible authoritarian styles. The 48-item Corporate Entrepreneurial Assessment Instrument (CEAI) 
(Hornsby, Kuratko \& Zahra, 2002) was measured on a seven-point Liker-type scale that varies from strongly disagree to strongly agree. The CEAI consists of 37 positive and 11 negatively worded items. The 20-item Minnesota Job Satisfaction Questionnaire (Weiss, Dawis, England \& Lofquist, 1967) measured job satisfaction on a five-point Likert scale varying from very dissatisfied to very satisfied. The 32-item MARKOR (Kohli, Jaworski \& Kumar, 1993) market orientation instrument was measured on a 7-point Likert scale varying from strongly disagree to strongly agree.

Researchers are confronted with certain challenges when applying psychometric instruments interculturally (Moschis, Ong, Abessi, Yamashita \& Mathur, 2013). Psychometric instruments are often not crossculturally applicable, which could lead to bias (Schwarz, 2003), jeopardising its validity (Van Eeden \& Mantsha, 2007). Due to the dilemma that instruments are often not portable to other cultures, the psychometric instruments were subjected to evaluation in this South African sample. Exploratory Factor Analysis was executed with direct quaritmin rotation of the axis. The instruments yielded the following factors, with Cronbach Alphas reported in brackets. The Khandwalla (1987) Flexibility scale had two factors: $\mathrm{F} 1=$ formal flexible practices (0.86); F2 = inflexible authoritarianism (0.64). The CEAI (Hornsby et al., 2002) produced the following eight factors: CE1 = work discretion (0.84); CE2 = management support and risk acceptance (0.82); CE3 = rewards/reinforcement (0.75); CE4 = innovative initiatives (0.84); CE5 = financial support (0.73); CE6 = sufficient time (0.76); CE7 = organizational boundaries (0.81); CE8 = inadequate time (0.76). The MARKOR (Kohli et al., 1993) scale yielded three factors: $\mathrm{MO} 1=$ intelligence generation $(0.81) ; \mathrm{MO}=$ inertia $(0.83) ; \mathrm{MO} 3=$ responsiveness $(0.74)$. The Minnesota Job Satisfaction Questionnaire consisted of two factors: (Weiss et al., 1967): JS1 = extrinsic (0.86); JS2 = intrinsic (0.85).

\section{RESULTS}

Pearson Product Moment Correlation between flexibility and corporate entrepreneurship, market orientation and job satisfaction is reported in Table 1.

Table 1: Pearson Product Moment Correlation between Flexibility, Corporate Entrepreneurship, Market Orientation and Job Satisfaction

\begin{tabular}{|c|c|c|c|c|c|c|c|c|}
\hline \multicolumn{1}{|c|}{ Flexibility } & CE1 & CE2 & CE3 & CE4 & CE5 & CE6 & CE7 & CE8 \\
\hline \multirow{2}{*}{ F1 Formal Flexibility } & 0.259 & 0.334 & 0.285 & 0.335 & 0.209 & -0.025 & -0.257 & -0.027 \\
& 0.0001 & 0.0001 & 0.0001 & 0.0001 & 0.0001 & 0.6479 & 0.0001 & 0.6247 \\
\hline \multirow{2}{*}{ F2 inflexible authoritarian } & -0.219 & -0.236 & -0.259 & -0.233 & -0.144 & -0.001 & 0.057 & -0.111 \\
& 0.0001 & 0.0001 & 0.0001 & 0.0001 & 0.0085 & 0.9790 & 0.0001 & 0.0427 \\
\hline & & & & & & & & \\
\hline Flexibility & MO1 & MO2 & MO3 & JS1 & JS2 & & & \\
\hline \multirow{2}{*}{ F1 Formal Flexibility } & 0.34623 & -0.210 & 0.2447 & 0.3877 & 0.3131 & & & \\
\hline \multirow{2}{*}{ F2 inflexible authoritarian } & $<.0001$ & $<.0001$ & $<.0001$ & $<.0001$ & $<.0001$ & & & \\
& -0.0896 & 0.2055 & -0.153 & -0.354 & -0.179 & & & \\
\hline
\end{tabular}

Table 1 indicates a significant positive relationship between formal flexibility and CE1, CE2, CE3, CE4, CE5, MO1, MO3, J21 and JS2 and a significant negative relationship with CE7 and MO2. Authoritarianism had an opposite significant negative relationship with CE1, CE2, CE3, CE4, CE5, MO3, J21 and JS2 and a significant positive relationship with CE7 and MO3. Concerning the relationship with CE, only CE6 (sufficient time) and CE8 (inadequate time) did not show a significant relationship with the flexible and inflexible scales.

The prediction of formal flexibility (F1) and inflexible authoritarianism (F2) was done by means of Hierarchical Multiple Regression Analysis, reported in Table 2 with the CE, MO and JS factors as independent variables. 
Table 2: Hierarchical Multiple Regression Analysis with Formal Flexibility and Inflexible Authoritarianism as Dependent Variables

\begin{tabular}{|c|c|c|c|c|}
\hline \\
\hline Variable & $\mathbf{F}(\mathbf{d f})$ & $p$ & $\mathbf{R}^{2}$ & $\mathbf{C}(\mathbf{p})$ \\
\hline \multicolumn{5}{|c|}{ Formal Flexibility (F1) } \\
\hline JS1 & $58.55(1: 332)$ & 0.0001 & 0.1503 & 38.7986 \\
\hline CE2 & $22.27(2 ; 331)$ & 0.0001 & 0.2040 & 17.5461 \\
\hline MO1 & $10.67(3 ; 330)$ & 0.0012 & 0.2290 & 8.7218 \\
\hline CE4 & $6.90(4 ; 329)$ & 0.0090 & 0.2449 & 3.8449 \\
\hline CE8 & $4.68(5 ; 328)$ & 0.0313 & 0.2556 & 1.2342 \\
\hline \multicolumn{5}{|c|}{ Inflexible Authoritarianism (F2) } \\
\hline JS1 & $47.42(1 ; 332)$ & 0.0001 & 0.12 .53 & 17.6607 \\
\hline CE2 & $7.48(2 ; 331)$ & 0.0066 & 0.1447 & 11.9763 \\
\hline CE7 & $5.03(3 ; 330)$ & 0.0256 & 0.1576 & 8.8720 \\
\hline $\mathrm{MO} 2$ & $4.23(3 ; 330)$ & 0.0405 & 0.1683 & 6.6200 \\
\hline
\end{tabular}

Formal flexibility (F1) and inflexible authoritarianism (F2) was predicted strongly and moderately 25.56 and 16.83 per cent respectively. Extrinsic job satisfaction (JS1) and management support and risk acceptance (CE2) played the major a role in the prediction of both F1 and F2.

Two structural equations models were built, with F1, formal flexibility and F2, inflexible authoritarianism as outcome variables (Figures 2 and 3 respectively).

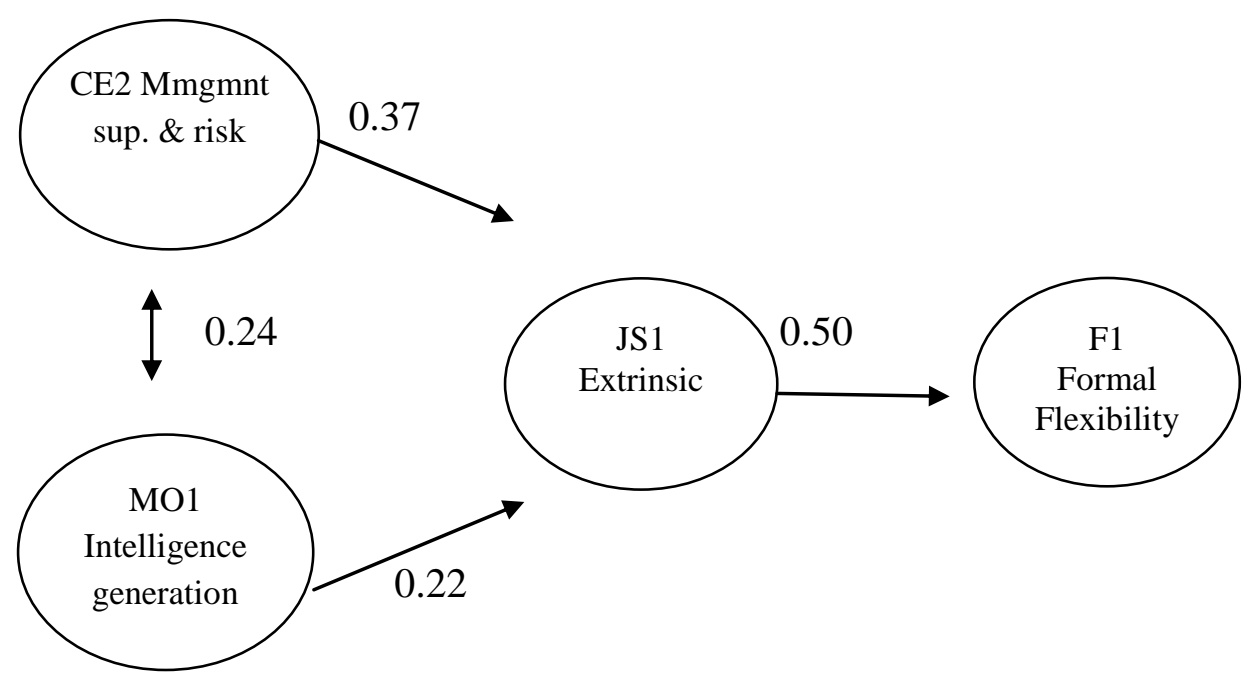

Figure 2: Structural Equations Model with Formal Flexibility as Outcome Variable

The Structural Equations Model in Figure 2 indicates a small (0.22), moderate (0.37) and large (0.50) effect. Confirmatory Factor Analysis shows an acceptable fit with the data: Goodness of Fit Index (GFI) $=0,8382$, GFI Adjusted for Degrees of Freedom (AGFI) $=0,8205$, Root Mean Square Residual (RMR) $=0,0748$, Chi-square $(\mathrm{df}=397, \mathrm{p}>$ Chi-square $<0,0001)=957.41$, RAMSEA Estimate $(90 \% \mathrm{Cl} 0.0599$ to $0.0705=0,0652$, Bentler's Comparative Fit Index $=0,8268$ and Bollen (1988) Non-normed Index Delta2 $=0,8389$. 


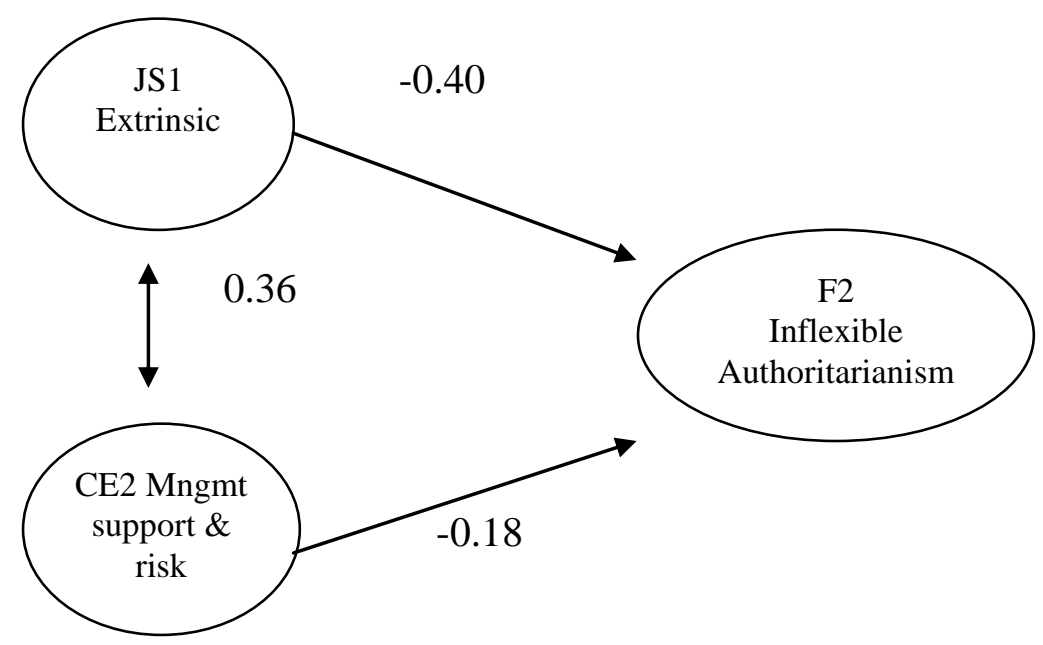

Figure 3: Structural Equations Model with Inflexible Authoritarianism as Outcome Variable

The Structural Equations Model in Figure 3 shows an insignificant $(-0,18)$ to moderate (between 0,36 and $0,40)$ fit with the data. Confirmatory Factor Analysis for this model shows a reasonable fit with the data with a Goodness of Fit Index (GFI) = 0,8799, GFI Adjusted for Degrees of Freedom (AGFI) $=0,8374$, Root Mean Square Residual $(\mathrm{RMR})=0,0584$, Chi-square $(\mathrm{df}=113, \mathrm{p}>$ Chi-square $<0,0001)=395.98$, RAMSEA Estimate $(90 \% \mathrm{Cl}$ 0,0776 to $0,0962=0,0869$, Bentler's Comparative Fit Index $=0,8555$ and Bollen (1988) Non-normed Index Delta2 $=0,8572$.

\section{DISCUSSION}

The findings of the Product Moment Correlation indicate the relationship of flexibility and inflexible practices with the work variables of CE, MO and JS as almost opposite sides of the coin. Where there is a significant positive relationship between CE1, CE2, CE3, CE4, CE5, MO3, JS1 and JS2 with formal flexibility, the relationship is significantly negative with inflexible authoritarianism. The current study found a significant positive correlation between formal flexibility and the following five corporate entrepreneurial factors:

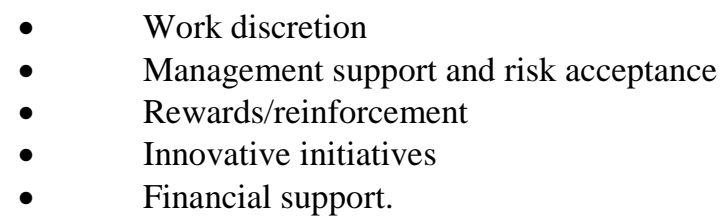

The significant positive relationship between flexibility and corporate entrepreneurship is consistent with the findings of Barrett and Weinstein (1998), as well as Barringer and Bluedorn (1999), of a significant positive correlation between corporate entrepreneurship and flexibility.

The significant positive relationship between MO1 (intelligence generation) and MO3 (responsiveness) with formal flexibility supports the findings of Grewal and Tansuhaj (2001) of a significant positive relationship between market orientation and strategic flexibility. Where the relationship is significantly negative between CE7 (organizational boundaries), MO2 (inertia) and formal flexibility, it is significantly positive with inflexible authoritarianism. This should serve as a warning to management of the possible adverse effects of organizational boundaries and inertia, limiting flexible practices.

Extrinsic job satisfaction and the corporate entrepreneurial factor of management support and risk acceptance played major roles in the prediction of both flexible and inflexible practices. The positive relationship between corporate entrepreneurial, market orientation and job satisfaction factors in the prediction of flexibility 
implies that management practices are the key to the facilitation of flexibility. Alternatively, too strict organizational boundaries and inertia is negatively related to flexibility and supportive of inflexible authoritarianism. These findings should serve as guidelines to management, as extrinsic job satisfaction and managerial support and risk acceptance could either contribute to formal flexibility or negatively influence inflexible authoritarian practices. The value added by this paper is to discern between the positive and negative outcomes of flexible and inflexible practices. These findings should serve as guideline in facilitating flexible practices of pursuing opportunities in meeting market demands.

\section{Limitations and Suggestions for Future Research}

The findings of the study are only generalizable to management in the industries and country, South Africa, represented by the sample. Future studies should consider representing countries other than South Africa, as well as other industries. Future studies could also investigate the relationship of other work variables with formal flexible or inflexible authoritarian practices.

\section{CONCLUSION}

This study has provided more insight into the positive and negative relationships of CE, MO and JS factors with formal flexibility and inflexible authoritarian practices. The results of this study should guide management in making informative decisions concerning CE, MO and JS practices that could enhance or inhibit flexible work practices. Management's sensitivity in promoting formal flexible practices should improve a firm's competitiveness and responsiveness in environmental uncertainty. Policy makers should take heed that organizational boundaries and inertia could jeopardize flexible practices. Management should act as agents in the facilitation of flexible operational systems.

\section{AUTHOR INFORMATION}

René van Wyk, $\mathrm{PhD}$, is an associate professor at the University of Johannesburg, Department of Industrial Psychology and People Management. She is an industrial psychologist, registered at the South African Health Professions Council. She is author of numerous peer-reviewed articles in organizational behaviour, positive psychological capital and familiness capital. She has supervised a number of masters' and doctoral students and has developed course material for a doctoral program in organizational behavior. E-mail: vanwyk.rene@gmail.com (Corresponding author)

Mandla Adonisi, PhD, is a senior lecturer at the Gordon Institute for Business Science in the areas or Organization Development, Leadership and Strategy. Dr Adonisi has previously lectured at the Wits Business School and the Public Development Management School. He is a visiting lecturer at the School for Business Leadership, UNISA, and teaches Change Management on the Harvard/WBS Senior Executive Program. He is a lead facilitator on the Leadership Development Program run by the Agricultural Economics Department at the University of Zimbabwe. In 1992, Mandla was awarded the British Council Fellowship for Post-graduate studies in Business Administration at Aston University (UK). E-mail: $\underline{\text { adonisim@gibs.co.za }}$

\section{REFERENCES}

1. Arief, M., Thoyib, A., Sudiro, A. \& Rohman, F. (2013). The effect of entrepreneurial orientation on the firm performance through strategic flexibility: A study on the SMEs cluster in Malang. Journal of Management Research, 5(3), 44-62.

2. Barrett, H. \& Weinstein, A. (1998). The effect of market orientation and organisational flexibility on corporate entrepreneurship. Entrepreneurship: Theory and Practice, 23(1), 57-67.

3. Barringer, M.S. \& Bluedorn, A.G. (1999). The relationship between corporate entrepreneurship and strategic management. Strategic Management Journal, 20, 421-444.

4. Bhardwaj, B.R. \& Momaya, K. (2006). Role of organizational flexibility for corporate entrepreneurship: Case study of FedEx Corporation. Global Journal of Flexible Systems Management, 7(1/2), 37-44. 
5. Bhattacharya, M. \& Giapponi, C. (2007). Outlay flexibility and organisational risk: Examining the relationship and its implication for firm returns. International Journal of Risk Assessment and Management, 7(4), 461-473.

6. Chen, A.H., Fabozzi, F.J. \& Haung, D. (2013). Optimal corporate strategy under uncertainty. Applied Economics, 45, 2877-2882.

7. Gjerding, A.N. (1999). The evolution of the flexible firm; New concepts and a Nordic comparison. Presented at the conference on National Innovation Systems. Industrial Dynamics and Innovation Policy organised by the Danish Research Unit for Industrial Dynamics, Rebild, Denmark. [Online] Available: http://www.druid.dk/uploads/tx_picturedb/ds1999-57.pdf

8. $\quad$ Grewal, R. \& Tansuhaj, P. (2001). Building organizational capabilities for managing economic crisis: The role of market orientation and strategic flexibility. Journal of Marketing, 65, 67-80.

9. Grobler, P.A. \& De Bruyn, A.J. (2011). Flexible work practices (FWP): An effective instrument in the retention of talent: A survey of selected JSE-listed companies. South African Journal of Business Management, 42(2), 63-78.

10. Guth, W. \& Gisnberg, A. (1990). Guest editors' introduction: corporate entrepreneurship. Strategic Management Journal, 11, 5-15.

11. Halemane, M.E. \& Janszen, F.H.A. (2004). Flexibility in operations and business innovation. Global Journal of Flexible Systems Management, 5(2/3), 23-41.

12. Hornsby, J.S., Kuratko, D.F. \& Zahra, S.A. (2002). 'Middle managers' perception of the internal environment for corporate entrepreneurship: Assessing a measurement scale', Journal of Business Venturing, 17, 253-273.

13. Kadir, S.L.S.A. \& Nadarjah, D. (2012). Development of measures for process flexibility: usefulness of focus group discussion approach. International Journal of Innovation in Business, 1(2), 134-315.

14. Keller, A.C. \& Semmer, N.K. (2013). Changes in situational and dispositional factors as predictors of job satisfaction. Journal of Vocational Behavior, 83(1), 88-98.

15. Khandwalla, P.N. (1987). Generation of pioneering-innovative management: Some Indian evidence. Organization Studies, 8(1), 39-59.

16. Kohli, A.K., Jaworski, B.J. \& Kumar, A. (1993). Markor: A measure of market orientation. Journal of Marketing Research, 30(4), 467-477.

17. Kukalis, S. (1989). The relationship among firm characteristics and design of strategic planning systems in large organizations. Journal of Management, 15, 565-579.

18. Kuye, O.L., Abiola, B. \& Oghojafor, B.E.A. (2013). Entrepreneurial game theoretic approach to planning flexibility and environmental scanning. International Business Research, 6(6), 95-104.

19. Moschis, G.P., Ong, F.S., Abessi, M., Yamashita, T. \& Mathur, A. (2013). Cultural and sub-cultural differences in reliability. Asia Pacific Journal of Marketing and Logistics, 25(1), 34-47.

20. Narver, J.C. \& Slater, S.F. (1990). The effect of a market orientation on business profitability. Journal of Marketing, 54(4), 20-35.

21. Olalekan, A. (2011). Strategic flexibility and market performance of SMEs in Nigeria. International Journal of Management and Enterprise Development, 10(1), 72-91.

22. Ramirez, A.M., Morales, V.G. \& Aranda, D.A. (2012). Knowledge creation and flexibility of distribution of information. Industrial Management \& Data Systems, 112(2), 166-185.

23. Reichert, M. \& Weber, B. (2012). Enabling Flexibility in Process-Aware Information Systems. Berlin: Springer.

24. Ribeiro-Soriano, D. \& Urbano, D. (2010). Employee-organization relationship in collective entrepreneurship: An overview. Journal of Organizational Change Management, 23(4), 349-359.

25. Sabbaghi, A. (2004). Global supply-chain strategy and global competitiveness. International Business \& Economics Research Journal, 3(7), 63-76.

26. Schwarz, N. (2003). Self-reports in consumer research: the challenge of comparing cohorts and cultures. Journal of Consumer Research, 29, 588-94.

27. Spector, P. E. (1997). Job Satisfaction: Application, Assessment, Cause, and Consequences. Thousand Oaks, CA: Sage.

28. Thatte, A., Rao, S.S. \& Ragu-Nathan, T.S. 2013. Impact of SCM practices of a firm on supply chain responsiveness and competitive advantage of a firm. Journal of Applied Business Research, 29(2), 499-530. 
29. Van Eeden, R. \& Mantsha, T.R. (2007). Theoretical and methodological considerations in the translation of the 16PF into an African language. South African Journal of Psychology, 37, 62-81.

30. Venieris, G. \& Cohen, S. (2008). Flexibility in manufacturing and activity based costing: modelling the interrelationships. Journal of Applied Business Research, 24(2), 81-96.

31. Weiss, D.J. Dawis, R., England, G.P. \& Lofquist, L.H. (1967). Manual of the Minnesota satisfaction questionnaire. St. Paul, MN: University of Minnesota.

32. Zortea-Johnston, E., Darroch, J. \& Matear, S. (2011). Business orientations and innovation in small and medium sized enterprises. International Entrepreneurship Management Journal, 8, 145-164. 


\section{NOTES}

